\title{
O corpo enquanto produto da escrita na fantasia*1
}

\section{The body as a product of writing in fantasy}

Janaina Bianchi de Mattos*2 Ana Maria Medeiros da Costa*3

A presente pesquisa se propõe a articular a relação entre corpo, escrita e fantasia, buscando verificar até que ponto o corpo pode ser efeito de uma escrita da fantasia ou produto daquilo que da fantasia não se escreve. A escrita deixa vestígios que apontam para o percurso da pulsão e podem revelar indícios dos suportes e construções corporais, evidenciando a fantasia que está em sua base.

Palavras-chave: Corpo, escrita, fantasia, lalangue

*1 Artigo científico extraído da dissertação de mestrado em psicanálise, intitulada Fantasia e escritas no corpo, orientada pela profa. dra. Ana Maria Medeiros da Costa, apresentada ao Programa de Pós-Graduação em Psicanálise da Universidade do Estado do Rio de Janeiro - UERJ, em 2017.

*2, ${ }^{3}$ Universidade do Estado do Rio de Janeiro - UERJ (Rio de Janeiro, RJ, Brasil) 


\section{Introdução}

Para Sigmund Freud, a vivência do corpo desde o início pressupunha um outro que atenderia a criança em seu desamparo, quando esta fosse invadida pelas necessidades de seu próprio corpo infantil e não pudesse dar conta disso sozinha. Jacques Lacan reafirma a presença desse Outro no circuito pulsional através da participação deste nas marcações corporais infantis, de modo que os "objetos $a$ " são instaurados por essa marcação no movimento libidinal, acentuando a aproximação entre corpo e linguagem.

Lacan aponta que é de uma experiência no corpo que se determinam as modalidades de gozo, e o sujeito externa isso que lhe marca o corpo através da repetição, que em seu funcionamento traz consigo uma parcela de gozo e é orientada pela fantasia. Na repetição, a pulsão comparece na experiência do sujeito em busca de Das Ding, seu objeto perdido. A fantasia é a busca de satisfação da pulsão no que esta se acha submetida ao princípio de prazer; mas como não é possível haver um objeto que satisfaça plenamente a pulsão, é a partir da repetição que o sujeito faz uma tentativa de satisfazê-la parcialmente.

Diante disso, surge a seguinte questão: o corpo se faz depositário das fantasias inconscientes, tornando-se palco de práticas ligadas a um gozo que trans-borda, ou seja, que se localiza nas bordas? Para responder esta questão, será utilizado um elemento precioso pertencente à proposta teórica de Lacan: a escrita. Significante e gozo marcam o corpo do sujeito, sendo responsáveis por uma escrita que indica que, aos poucos, aquilo que era apenas gozo de bordas vai encontrando meios de circulação no próprio corpo a partir da linguagem, que é sempre endereçada ao Outro. 


\section{ARTIGOS}

A escrita participa desta circulação, transportando restos de uma operação que nunca é definitivamente concluída entre o sujeito e o Outro: a separação. Deste modo, o processo de alienação e separação ocorre justamente em torno de tais bordas, que nada mais são que o corpo do sujeito com seus orifícios erógenos, sendo que este processo se dá ao longo da vida do sujeito indefinidamente.

Assim, como o sujeito nunca se separa completamente do Outro e permanece ligado a este por meio de suas bordas, ele passa a buscar um meio de se organizar minimamente com o gozo mortífero proporcionado por tal vinculação, e a saída que se lhe apresenta diante desse evento é a da fantasia. Podemos inclusive dizer que o sujeito trata o real proveniente de sua não separação do Outro de um modo corporal, estabelecendo com isso a fantasia.

Dessa forma, se o sujeito estabelece a fantasia a partir de sua confrontação com o real e se toda escrita é tentativa de inscrição de um real em causa, o corpo seria efeito da escrita da fantasia? Ou seria proveniente daquilo que da fantasia não se escreve?

\section{Linguagem, pulsão e construções corporais}

Lacan aponta que "o que é do Trieb cada um o emprega como designação de uma espécie de dado radical de nossa experiência" (Lacan, 1973/2008a, p. 160). Assim, esclarece que na experiência sempre se evidencia algo de irreprimível, mesmo através das repressões e que, justamente o fato de haver ali repressão, indica que há algo que está a todo momento a escapar dessa barreira, e isso que escapa é a pulsão com seu caráter arcaico e primordial.

Freud (1915/2007b) adverte que o estímulo pulsional não provém do mundo exterior, mas do próprio organismo, pois o sistema nervoso está constituído de modo a se livrar dos estímulos que lhe chegam e diminuí-los ao mínimo possível. As pulsões são decantações da ação de estímulos exteriores que no curso da filogênese influíram sobre a substância viva, modificando-a, por isso são numerosas, vindo de múltiplas fontes orgânicas, no começo atuando com independência umas das outras, e depois se reunindo em uma síntese mais ou menos acabada, de modo que a meta à qual aspiram é poder alcançar o prazer do órgão.

De acordo com Lacan (1973/2008a), “a pulsão se apresenta em uma montagem como não tendo pé nem cabeça, no sentido em que se fala de montagem numa colagem surrealista" (p. 167). Desse modo, a pulsão, com 
relação ao seu fim, se organiza numa amarração semelhante ao que é proposto pelo movimento surrealista, ou seja, não há simplesmente uma reversão em algo oposto na pulsão, mas sim uma constante transformação intercalada e contínua "das mais homogêneas imagens de umas para as outras" (p. 167). Será este o caminho que Freud nos indica para alcançar a essência da pulsão, que Lacan classificará como o "traçado do ato" (p. 167). A sexualidade sempre se manifesta em forma de pulsões parciais por conta do sistema nervoso central que opera de modo a garantir certa homeostase das tensões internas, uma vez que "a pulsão é precisamente essa montagem pela qual a sexualidade participa da vida psíquica de uma maneira que se deve conformar com a estrutura de hiância que é a do inconsciente" (p. 174). Isso esclarece porque a sexualidade só se realiza por meio das pulsões parciais no que se refere à sua finalidade biológica e que, assim, o corpo terá que se aparelhar daquilo que diz respeito à dialética do desejo, evidenciando que um corpo não está dado a priori; ele se constrói à medida que esae aparelhamento é concebido.

A volta em circuito da pulsão, num terceiro tempo, permite que apareça ali um sujeito que, para Lacan, é propriamente o outro e aparece de acordo 336 com o que a pulsão pode fechar de seu curso circular. "É somente com sua aparição no nível do outro que pode ser realizado o que é da função da pulsão". Tal constatação é oportuna quanto ao tema do corpo, pois permite pensar que a incidência do circuito pulsional a nível corporal, e a própria construção de um corpo somente ocorre com a entrada em causa do outro. Mas de que outro se trata aqui? Qual é o outro ao qual Lacan se refere no que tange à pulsão e ao corpo constituído com suas bordas, que são a "zona dita erógena na pulsão [...]” (idem, p. 175-176)?

A sexualidade se encontra de fato referida a um processo orgânico, porém não há uma maturação automática da pulsão, ou seja, a pulsão não passa por uma metamorfose natural de oral a anal, por exemplo, mas se altera devido à intervenção de algo da ordem da demanda do Outro. Por conta do efeito da fala, o sujeito sempre buscará se realizar no Outro, deixando claro que através do efeito da linguagem só há sujeito a partir de um assujeitamento deste ao campo do Outro (idem, p. 184).

A sexualidade somente exerce sua atividade própria por intermédio das pulsões parciais que têm uma circularidade do impulso, saindo através da borda erógena para retornar a ela contornando o objeto $a$; será desta forma que o sujeito irá atingir aquilo que é a dimensão do Outro. A pulsão estará encarregada de ir buscar algo que sempre responderá no Outro, de modo 
que todo este movimento terá também relação com o amor, pois para Freud o amor provém da capacidade do eu de "satisfazer de maneira autoerótica, por uma ganância de um prazer do órgão, suas pulsões parciais" (Freud, 1915/2007b, pp. 132-133).

A pulsão apresenta como instrumento um órgão que é inapreensível e, segundo Lacan (1973/2008a), se situa em relação ao verdadeiro órgão. Esse órgão será designado lâmina, o que sobrevive a qualquer divisão, ou seja, aquilo que é imortal. "Essa lâmina ou órgão que tem por característica não existir, mas que não é por isso menos um órgão, é a libido", afirma Lacan, e ainda acrescenta que "é a libido, enquanto puro instinto de vida, quer dizer, de vida imortal [...] de vida que não precisa, ela, de nenhum órgão, de vida simplificada e indestrutível" (Lacan, 1973/2008a, p. 193). Essa libido tem como equivalentes todas as formas possíveis de objetos $a$. Aqui fica claro que o objeto $a$ é objeto da fantasia e representante da libido, que é um órgão que se situa em relação a outro órgão; sendo assim, poderíamos pensar na fantasia como estando libidinalmente localizada no corpo? Será que este "outro órgão" poderia ser o corpo enquanto organismo vivo? Justamente pela libido ser representada por aquela parte de si mesmo que o indivíduo perde ao nascer é que ela pode ser apreendida como o mais profundo objeto perdido (idem).

O que define a relação primordial que o sujeito estabelece com o Outro é que, acima de tudo, ele começa no lugar do Outro, pois é lá que desponta o primeiro significante. Por isso, para ser sujeito, no sentido de estar barrado por ser determinado pela linguagem, o infans primeiro precisou ir ao campo do Outro e recortar dali aquilo que para ele será o seu significante mestre, einziger zug, o seu $\mathrm{S}_{1}$.

Sabemos que "um significante é aquilo que representa o sujeito para outro significante", ou seja, o sujeito é aquele que se faz representar em meio a significantes. Lacan (1973/2008a) pontua que "o sujeito nasce no que, no campo do Outro, surge o significante" e que "por este fato mesmo, o que não era nada senão sujeito por vir, se coagula em significante" (p. 193). Ao cruzar as fronteiras da relação com o Outro, ocorre um encontro com um significante que permite que este pedacinho de real que era constituído apenas por bordas e orifícios passe então a ser um sujeito e a estar atravessado pela linguagem; a partir daí esse sujeito será também um significante coagulado, ou seja, ele passa a ser esse significante que "recebeu" do Outro se fazendo representar por isso para outros significantes. Essa relação ao Outro faz surgir a lâmina, isto é, a libido como herança daquilo que é perdido na passagem para o estatuto de sujeito enquanto marcado pelo ciclo sexual, de modo que é 
a partir disso que a pulsão terá duas faces respectivamente: a de presentificar a sexualidade no inconsciente e a de representar a morte.

Para a psicanálise, o corpo se constitui a partir do Outro da linguagem. Nas trocas entre mãe e filho há uma inscrição dos significantes maternos no corpo do infans que são ativadas pela pulsão, cavando uma borda e erogeneizando. O mapa da sexualidade infantil é traçado aí, ao longo desses primeiros cuidados, em que a pele, os orifícios corporais, as sensações advindas do toque, o cheiro, a voz, o olhar, enfim, todo o movimento erótico construído entre mãe e bebê é acolhido pela estrutura significante da primeira, que, transmitindo algo disso ao filho, possibilita a ele a construção de um corpo para si (Mieli, 2002).

Fora da linguagem não há corpo e nem pulsão, pois a pulsão nada mais é do que o significante marcando o corpo. A libido é a energia da pulsão e Lacan a chama de órgão para indicar que o corpo é libido e que só assim ele é corpo. Não há nada no corpo do sujeito que não seja habitado pela linguagem, de modo que mesmo o bebê ainda no útero da mãe já está inserido na linguagem, pois participa do corpo materno, que é composto por significantes próprios.

Para Lacan, a pulsão deve ser concebida como efeito da demanda do 330 Outro da linguagem, em uma incidência muito precoce sobre o sujeito ainda em constituição. Por isso, pontuará que "as pulsões constituem o eco no corpo do fato de que há um dizer" (Lacan, 1975-76/2007, p. 18). Em sua retomada da teoria freudiana, Lacan volta ao texto "Pulsões e destinos da pulsão", no qual Freud (1915/2007b) defende que "uma pulsão nos aparecerá como um conceito fronteiriço entre o psíquico e o somático, como um representante psíquico dos estímulos que provêm do interior do corpo e alcançam a mente, exigência de trabalho que é imposta à mente em consequência de sua ligação com o corporal" (p. 164). A partir daí, Lacan aponta que o que Freud apresenta com tal construção teórica é que se trata de um destacamento da ação da linguagem em certas bordas orificiais responsáveis por efetivar a função de troca com o Outro. O efeito causado por esse Outro nas estruturas de borda é a construção daquilo que Freud denominou de zonas erógenas. Lacan apresenta a ação do significante sobre o organismo biológico no centro do circuito pulsional.

Freud e Lacan irão evidenciar o fato de que na pulsão entra em cena algo que é da ordem do impossível no que diz respeito à sua satisfação, deixando claro que sempre há algo na própria natureza da pulsão desfavorável à sua realização. Quanto ao objeto da pulsão, este é tido como indefinido e de natureza variável, e a partir desta constatação, Lacan propõe o conceito de objeto causa de desejo, o objeto $a$. 


\section{ARTIGOS}

Quanto à pulsão, Freud, ao longo de sua teoria, notou que mesmo em face de situações de conteúdo totalmente desprazeroso, o sujeito ainda assim se mantinha na repetição, de modo que foi preciso avançar teoricamente para mais além do princípio de prazer, onde notou a questão enigmática da pulsão de morte. A partir desse ponto, Lacan constatou que, ao mesmo tempo que as pulsões sexuais visam ao objeto $a$ com sua cobertura imaginária $i(a)$, a pulsão de morte se endereça a Das Ding, ou seja, ao gozo, que está mais além tanto do princípio de prazer quanto do princípio de realidade. O circuito da pulsão contorna o objeto $a$ enquanto objeto perdido e, para tanto, persegue sua face simbólico/imaginária. Porém, sua maior faceta tem relação com o real, que aponta para o mais-de-gozar, que é da ordem do impossível. Esta falta originária de objeto no que se refere à pulsão remete a um furo que é a parcela real do inconsciente e em torno desse furo, o inconsciente se estrutura enquanto linguagem, índice do simbólico.

\section{A construção do corpo a partir de sua escrita nas bordas}

A construção corporal se passa nas relações primárias do sujeito, onde o signo do Outro é impresso nas bordas orifíciais que tecem os traços desse corpo em formação. As bordas são justamente todo esse movimento relacional que possibilita uma delimitação dessas fronteiras corporais.

No processo de construção das bordas e fronteiras corporais, o sujeito fica capturado, ou seja, colado ao signo do Outro, que o remete a um lugar objetal, posteriormente ligado a uma construção fantasmática. A letra está inscrita aí, nesse espaço fronteiriço entre o corpo materno e o corpo ainda em formação do infans, dando os contornos particulares e bordejando este novo corpo, servindo de cápsula onde estará contido o enigma representado pelo Outro, base das posteriores construções fantasísticas do sujeito. Assim, se a letra é signo do Outro e também responsável por contornar e construir as bordas do corpo do bebê é possível intuir que o corpo é composto por traços do Outro enquanto enigma. $\mathrm{O}$ corpo do sujeito seria a própria representação do enigma do Outro?

Significante e letra são registros diferentes entre si, de modo que não é possível a um substituir o outro. A letra está situada do lado do real, e o significante do lado do simbólico. Para diferenciar letra e significante, Lacan separa fronteira e litoral, apontando que na fronteira há algo da ordem da tradução, pois é ali que a relação com o significante se coloca; o litoral é da 
ordem do impossível, da ordem do real, como o sotaque, que é um resto e que se localiza no corpo.

Nosso organismo é desnaturado, não tem como medir o que é produto orgânico, simbólico, imaginário e real. Os membros do corpo, mesmo os órgãos internos, são bordas. A representação que Lacan faz do corpo é da garrafa de Klein que aponta para o fato de que dentro e fora estão ligados de forma contínua e ininterrupta; isto quer dizer que quando o bebê mama, ele não mama apenas o leite, mas os traços do Outro que vêm junto com esse leite. Esses traços são sígnicos e trazem consigo a voz e o olhar do Outro, colocando em evidência que o metabolismo do corpo responde a uma relação direta ao signo que o Outro porta.

O Outro é o lugar onde se situa a cadeia do significante, responsável por comandar tudo o que irá se presentificar do sujeito, é o campo do vivo, onde o sujeito aparece; e será do lado desse vivo, da libido, que o sujeito será chamado à subjetividade e que se manifestará essencialmente a pulsão. $\mathrm{O}$ processo de constituição do eu (je) tem início com a identificação, que ocorre sobre as bases de uma alienação fundamental ao Outro primordial. Esse processo apresenta como suporte a função cativante da imagem e vai ocorrer ao longo de toda a vida do sujeito. $\mathrm{O}$ "significante produzindo-se no campo do Outro faz surgir o sujeito de sua significação", porém, o significante reduz o sujeito a não ser mais que um significante e o petrifica no mesmo movimento que o convoca a operar enquanto sujeito, na pulsação temporal do inconsciente, mais precisamente no fechamento. É aqui que o sujeito se afanisa (Lacan, 1973/2008a, p. 203).

Nesse nascimento do sujeito no campo do Outro, em que ele irá se petrificar, e ao mesmo tempo se afanisar no primeiro significante que surge aí e, no que esse primeiro significante representa o sujeito para outro significante, diz respeito ao einziger zug, ou seja, ao traço unário, que posteriormente Lacan irá chamar de $\mathrm{S}_{1}$ da série de significantes. Esse primeiro movimento, na pulsação e circularidade do inconsciente, é referente à alienação. No entanto, quando o sujeito aparece em algum lugar enquanto sentido, isto é, quando se encontra com esse primeiro significante vindo do campo do Outro, logo ele também desaparece por conta do significante binário, vorstellungrepräsentanz, que também pode ser nomeado de $\mathrm{S}_{2}$, que será apreendido como o representante da representação (idem).

Freud (1915/2007a) esclarece que existem razões para supor um recalque primordial, uma primeira fase do recalque, consistindo em que o representante (representanz) psíquico da pulsão, ou seja, o representante da representação, 


\section{ARTIGOS}

não é admitido no consciente, estabelecendo-se, assim, uma fixação. A partir desse momento, o representante da representação em questão permanece imutável e a pulsão segue ligada a ele. Na segunda etapa do recalque, que seria o recalque propriamente dito, a pulsão se liga aos restos psíquicos do representante da representação reprimido e, por conta desse vínculo, tais representações experimentam o mesmo destino que o recalque primordial (idem, p. 143).

É importante ressaltar que não há sujeito sem que, em algum lugar, ocorra sua afânise, sendo nessa divisão fundamental que se constitui o cerne da alienação, instituindo a dialética do sujeito. Assim, "por causa do vel, ponto sensível, ponto de balanço, só há surgimento do sujeito no nível do sentido por causa de sua afânise no lugar Outro, que é do inconsciente" (Lacan, 1973/2008a, p. 221). A pulsão, por sua vez, só pode ser reconhecida naqueles objetos que, no final das contas, não podem servir pra nada. Esses objetos são chamados por Lacan de objetos $a$ e podem ser representados pelo seio, fezes, olhar e voz. É nesse ponto que se introduz a dialética do sujeito enquanto sujeito do inconsciente (idem).

Lacan retoma Freud no que se refere à função da identificação e descobre em sua escrita que Freud relaciona amor e identificação num certo registro, bem como narcisismo e superestimação do objeto como idênticos no amor. É justamente na segunda forma de identificação que Lacan identifica e destaca o einzigerzug, o traço unário, que será o fundamento, o núcleo do ideal do eu. $\mathrm{O}$ traço unário não se situa no campo primeiro da identificação narcísica, ao qual Freud relacionara a primeira forma de identificação, que corresponderia a um tempo mítico em que o pai seria colocado como o primeiro investimento libidinoso, anterior à mãe.

Para Lacan (1973/2008a), "o traço unário, no que o sujeito a ele se agarra, está no campo do desejo, o qual só poderia de qualquer modo constituir-se no reino do significante, no nível em que há relação do sujeito ao Outro" e ainda acrescenta que "é o campo do Outro que determina a função do traço unário, no que com ele se inaugura um tempo maior da identificação na tópica então desenvolvida por Freud, a saber, a idealização, o ideal do eu" (p. 248). Aqui se faz importante diferenciar o campo do ideal do eu do campo do eu ideal que Lacan diz surgir no estádio do espelho e que diz respeito a um ponto em que o sujeito deseja comprazer-se em si mesmo.

Porém, o recalque não impede o representante da pulsão de seguir existindo no inconsciente. Esse representante se desenvolve com maior riqueza e menores interferências quando o recalque o subtraiu do fluxo 
consciente, de modo que se prolifera nas sombras e encontra formas extremas de expressão, causando no neurótico uma sensação de que possui uma intensidade pulsional extraordinária e perigosa (idem).

A criança busca no Outro um signo "imagem de a i(a)", capaz de representar a aprovação deste com relação à sua imagem. $\mathrm{O}$ olhar do Outro será interiorizado por meio de um signo, einzigerzug, que constituirá a base do ideal do eu (moi), que é simbólico e será diferenciado da projeção imaginária do eu ideal. Lacan, no seminário 9, sobre a identificação, aborda a expressão einzigerzug, traduzindo-a por traço unário, e a articula com a função do um (apud Mieli, 2002).

O traço seria o próprio signo de aprovação e, portanto, também enigma do Outro; afinal, é completamente enigmático para o sujeito saber o que constitui o alicerce do desejo do Outro, ou seja, há uma interrogação referente ao modo como essa aprovação se dá. O traço é correlato ao traço unário e preenche a fenda que o sujeito recebe do significante, e, a partir daí, passa a haver a possibilidade de um reconhecimento da unidade imagem $i(a)$, desde que essa seja autenticada pelo Outro enquanto signo (Mieli, 2002).

A partir daí, passa a ser possível compreender o traço como o que estabiliza a imagem especular e possibilita certa satisfação narcísica ligada ao eu ideal. Deste modo, o traço é responsável por fixar no corpo sua imagem e sendo o representante da repetição, é a forma mais simples de marca, ou seja, de elemento da escrita, por ser a origem última do significante.

Neste sentido, então, poderíamos pensar o corpo como sendo uma forma de escrita que se propõe a inscrever o traço unário, isto é, o signo do Outro que esse traço inaugura. Os detritos transportados pela escrita são expressão do sujeito que se manifesta entre o eu e o Outro e são exatamente esses detritos que irão compor a singularidade do corpo.

Essa letra, enquanto resto produzido na relação com o Outro, faz as bordas desse corpo e, enquanto portadora desse enigma que representa o Outro, também é suporte das fantasias do sujeito, bem como de seu endereçamento que já estará contido em seu núcleo. O sujeito externa isso que lhe marca o corpo através da repetição, que em seu funcionamento traz consigo uma parcela de gozo e é orientada pela fantasia, que nada mais é do que um modo de tentar satisfazer a pulsão.

A fantasia é produto da pulsão, no sentido de ser conduzida por ela ao mesmo tempo que é destinada a dar conta da mesma; ela seria edificada para tentar satisfazer a pulsão de um modo possivelmente aceito pela realidade. Por isso, Freud caracterizou a fantasia como a busca de satisfazer duas exigências 
fundamentais do sujeito: a exigência pulsional, que pressionaria o sujeito a obter satisfação a qualquer custo e a renúncia exigida pela realidade que o impediria de obter a tão almejada satisfação pulsional.

\section{Corpo: escrita da fantasia?}

O alvo da pulsão de morte é o gozo e a fantasia impede que se esteja totalmente submetido a esse alvo que é mortífero. A partir da fantasia, o que era pura pulsão de morte se sexualiza, transformando-se parcialmente em pulsão de vida. A fantasia se instaura a partir do recalque primário (ou originário), que implica o recalque do real, e funda o advento do sujeito. Posteriormente, viria o recalque secundário, que estaria na base dos sintomas neuróticos e efetivaria o recalque da fantasia que havia sido instaurada no primeiro recalque (Jorge, 2010, p. 65).

Esse real que é recalcado a partir do recalque primário é base da pulsão de morte, início de tudo. Porém, para dar conta desse real absoluto, o sujeito recorre ao Outro e procura em seu signo um meio de estabelecer a fantasia. Nesse movimento em que a fantasia surge enquanto produto do recalque originário, o que ocorre é um afunilamento do gozo que invadia todo o corpo do sujeito e, com isso, uma inescapável redução de sua conotação mortífera. O gozo não será mais pura manifestação da pulsão de morte, pois irá se localizar de forma mais restrita, em locais privilegiados do corpo, as bordas orificiais. Assim, podemos calcular que o resultado dessa operação complexa será o sujeito em um movimento contínuo de identificação e separação ao signo do Outro a partir de suas bordas orificiais, e o fio invisível e condutor dessa ligação será a fantasia.

Após todo esse processo, o sujeito será barrado, pois estará atravessado por uma falta decorrente do fato de somente poder ter acesso ao gozo de forma parcial. Desse modo, a fantasia desempenhará o papel de tentar indicar ao sujeito aquilo que falta, apontando sempre em direção ao objeto $a$, objeto faltoso. No entanto, esse objeto, que opera enquanto causa de desejo, só pode ser acessado parcialmente enquanto palavra (simbólico) e imagem (imaginário), e esse acesso se dará por meio da fantasia. Já a face real do objeto $a$, essa nunca poderá ser abordada, pois diz respeito à pulsão de morte e se refere a Das Ding, a Coisa, que proporcionaria gozo absoluto caso fosse possível de ser atingida (idem, p. 84). 
Pelo fato de a fantasia sexualizar a pulsão de morte, ela também está vinculada ao processo de erogenização do corpo todo e especialmente dos orifícios corporais, que são as regiões privilegiadas sobre as quais a demanda do Outro incide, pois aquilo que era apenas real passa a ser borda feita por linguagem e ligada a uma imagem. Com isto, o corpo será fundamentalmente reduzido a gozos parciais, que giram em torno de suas zonas erógenas.

Desta forma, seguindo tal linha de raciocínio, podemos entender que a fantasia se constitui no movimento de dar contorno ao furo no real, fechando o acesso ao gozo absoluto e inaugurando o sujeito dividido. Assim, como a fantasia é feita para "tratar" do real, ela é inicialmente elaborada com algo que diz respeito ao próprio real, a saber, o gozo e, mais precisamente, com algo muito particular referente ao gozo: o corpo.

A fantasia possibilita ao sujeito permanecer fixado em certos fragmentos excessivamente investidos do corpo. Esses fragmentos são, na verdade, os objetos da pulsão convertidos em objetos da fantasia. Assim, como o objeto da pulsão é o objeto $a$, o objeto da fantasia também o será. Partindo dessa constatação, podemos compreender claramente a fórmula lacaniana da fantasia: $\$ \diamond a$ : sujeito barrado, todas as formas possíveis de acesso ao objeto $a$, bem como a fórmula da pulsão, que nos evidencia que $\$ \diamond \mathrm{D}$, sujeito barrado, todas as formas possíveis de demanda. Logo, podemos constatar que é a partir da demanda do Outro incidindo no corpo do sujeito que a fantasia é constituída, pois ela visa dar conta desta, propondo-se a alcançar o objeto perdido. Todo esse movimento se operacionaliza nas bordas, fato que é evidenciado nas próprias fórmulas em que a punção, que é o símbolo das bordas, se encontra no centro.

Diante dessa demanda, o que se evidencia é o desejo enigmático do Outro, que o sujeito vivencia como um apelo ao gozo, de modo que a única saída encontrada para se confrontar com isso é a fantasia. Partindo de tais pressupostos, é possível chegar à formulação de que a fantasia é construída com o que o sujeito percebe de mais concreto enquanto sexuado e movido pela pulsão: o corpo. É com o corpo que a fantasia se formula e faz barreira ao gozo.

A partir disso, precipita-se a seguinte questão: se o sujeito trata o real de um modo corporal, estabelecendo com isto a fantasia, e se toda escrita é tentativa de inscrição de um real em causa, o corpo seria efeito da escrita da fantasia ou daquilo que da fantasia não se escreve?

A fantasia pode ser entendida como uma maneira que o sujeito encontra de se organizar diante da expectativa, da aflição ou da angústia provocadas 


\section{ARTIGOS}

pelo enigmático e assustador desejo do Outro. Para dar conta de suportar a resposta que virá contida na questão que ele mesmo endereça ao Outro: "che vuoi?", que é possível ler como "quem sou?" ou "que queres de mim?". O sujeito extrai de sua própria substância corporal o suporte imaginário para construir a fantasia. Esse suporte será $i(a)$, ou seja, a cobertura imaginária do objeto $a$, objeto da pulsão revestido de imaginário, que o sujeito utiliza para transformar em objeto da fantasia (idem, p. 79).

A fantasia é uma montagem imaginária construída sobre a montagem da pulsão. Desta forma, é uma ação que se organiza segundo os contornos do objeto pulsional. Vendo-se surpreendido pelo enigma do desejo do Outro, o sujeito se restabelece fazendo uso de uma imagem que lhe servirá de apoio. Essa imagem é $i(a)$ e convoca o sujeito a mergulhar no real, para assim se identificar com o objeto e, com isto, poder torná-lo de objeto da pulsão em objeto da fantasia (idem, p. 89).

Esse percurso do sujeito com o Outro permite que haja um investimento, por parte do primeiro com relação a uma imagem significante, e isso significa supor-lhe uma destinação, o que causa efeitos imediatos no real do corpo. É efetivamente por essa capacidade de causar algo no corpo que essa imagem é dotada de valor significante. Assim, a fantasia ocorre quando a imagem é adotada pelo sujeito como resposta ao enigma do Outro (idem, p. 82).

Essa imagem i(a) é primordial aqui, pois ela diz respeito tanto à imagem de um corpo refletido no espelho, que é sempre parcial e compósito, e nunca total e pleno (imaginário), quanto ao signo (real) e ao significante (simbólico). Signo porque traz em si o cerne da presença do Outro com seu desejo, e significante por levar ao agir da fantasia, ou seja, à ação de fantasiar. Esse signo/traço revela que o sujeito permanece em contínuo processo de alienação/separação ao Outro e que a fantasia será o centro de tal processo, sendo, por sua vez, movida pela pulsão que visa a $i(a)$.

\section{A fantasia originária nos embalos de lalangue}

As fantasias originárias, para Freud, dizem respeito às cenas primárias ligadas à castração e à sedução. Além disso, apontam para uma universalidade que estaria relacionada a uma transmissão filogenética a qual representaria os primórdios da família humana. Essa herança filogenética que estaria no cerne das fantasias originárias tem relação com o que Freud nomeou de recalque orgânico, ou seja, ele não só admite como ressalta em alguns momentos 
relevantes ao longo de sua obra, que haveria algo de orgânico na origem do recalque. Esse recalque estaria relacionado com o período na história da humanidade em que a "posição ereta" foi adotada, fazendo com que o olfato fosse substituído pela visão, de forma que, para Freud, o advento da postura ereta no homem levou à atrofia do sentido do olfato, que teve como consequência o recalque orgânico do prazer do cheiro e, com isto, o recalque da sexualidade em geral (Jorge, 2000).

O recalque originário diz respeito ao recalque do real, que, ao fundar o simbólico do inconsciente e da pulsão, instaura a fantasia fundamental, possibilitando o advento do sujeito, o indivíduo da espécie. Já com relação ao recalque secundário, que estaria na base dos sintomas neuróticos, este seria o responsável pelo recalcamento da fantasia, que teria sido "instaurada pelo recalque primário ou originário". Para dar sequência ao processo, teríamos o retorno do recalcado, que seria o retorno da própria fantasia pela via de seu derivado sintoma (Jorge, 2010).

Freud relaciona pulsão e filogênese, em sua definição de pulsão entre 1905 e 1914, "incluindo o corpo como portador da história da espécie" (Jorge, 2000, p. 49), sendo então um corpo filogenético e, portanto, corpo 346 pré-histórico. O que teria restado desse corpo pré-histórico seria da ordem de uma pulsão olfativa, pois justamente sua prevalência que foi perdida pela espécie humana ao adotar a postura ereta. O recalque orgânico seria "o momento zero do recalcamento" (idem, p. 58) e, portanto, o próprio elemento fundador da espécie humana; nessa passagem teria havido a perda da ação predominante dos estímulos olfativos sexuais, cuja característica é a de obedecerem rigidamente a fatores biológicos cíclicos. A sexualidade passou a ser regida pela pulsão cuja força, sublinha Freud, é uma força constante.

Para Lacan, gozo seria o correlativo em Freud da satisfação da pulsão, no sentido de uma tentativa de satisfação, pois sabemos que, efetivamente, a pulsão não pode ser satisfeita. O gozo estará sempre ligado à pulsão de morte, porém apresentando-se em diferentes modalidades: gozo fálico, que seria sexual, parcial e limitado; gozo Outro, que se apresentaria como não sexual e ilimitado. Como já foi dito anteriormente, a fantasia seria a tentativa de transformar o gozo não sexual e ilimitado (gozo Outro) em um gozo sexual e limitado (gozo fálico). Essa limitação se presentificaria nos orifícios corporais e apontaria para aquilo que falta, puncionando do sujeito barrado o objeto $a$, como nos mostra a fórmula $\$ \diamond a$.

A partir das formulações levantadas até aqui, podemos compreender que o infans, em seus primeiros momentos de vida, já vem ao mundo 


\section{ARTIGOS}

submetido ao recalque orgânico da espécie e, por conta disso, irá se encontrar completamente desprovido de qualquer saber instintual que pudesse vir a lhe servir nesse momento. Dessa forma, esse pequeno pedacinho de carne notará que se encontra mergulhado nas águas da linguagem materna que, no momento em questão, se presentifica apenas por ser uma voz... Lalangue, como o próprio Lacan irá nomear em muitos momentos de seu ensino.

Nesse momento, não há sujeito, apenas um ser que não dispõe do recurso do instinto e está mergulhado em uma sonoridade que the embala em movimentos descompassados, ao mesmo tempo que faz marcas em seu corpo. Essas marcas seriam os restos da melodia materna que são feitos de um fora do sentido, fora da cadeia, apenas em coalescência com o gozo (Mieli, 2002).

Já num segundo momento, o infans vivencia os efeitos do recalque originário, onde as manifestações pulsionais começam a ser demarcadas e imobilizadas em si, convertendo-se em restos passivos que irão constituir o corpo deste "protosujeito", que poderá vir a ser sujeito de acordo com a resposta que puder oferecer à invocação (voz) desse Outro no qual se encontra apenas mergulhado, sendo Um com o Outro.

Esse mergulho, essa submersão é em lalangue... O infans está mergulhado em lalangue, na melodia da voz materna, sendo que "em tudo o que há de mais íntimo e inacessível no uso subjetivo da língua ressoa lalangue e isto é o que constitui a particularidade do ser humano" (Mieli, 2002). Nesse sentido, Lacan (1973/2003) dirá que o inconsciente é estruturado como uma linguagem, isto é, "como a lalingua que ele habita"; e prosseguirá dizendo que "uma língua entre outras não é nada além da integral dos equívocos que sua história deixou persistirem nela. É o veio em que o real se depositou ao longo de eras" (Lacan, 1973/2003, p. 492). A partir disso, fica entendido que o inconsciente se estrutura sobre as bases de lalangue, e essa base sonora traz consigo um emaranhado vocal que aponta para o fato de que a língua, com seus equívocos, constituiria o sujeito, inscrevendo-o na linguagem.

Aqui, neste ponto, torna-se perceptível a operação do recalque originário: ocorre o recalcamento desse real, que diz respeito a lalangue, e, com isto, a fundação do simbólico, do inconsciente e da pulsão, instaurando, assim, a fantasia fundamental ou fantasia originária. Desta forma, podemos dizer que a fantasia fundamental ou originária é edificada a partir de lalangue e Lacan (1975/2008b) nos confirma isso ao afirmar que:

Alingua nos afeta primeiro por tudo o que ela comporta como efeitos que são afetos. Se podemos dizer que o inconsciente é estruturado como uma 
linguagem, é no que os efeitos de alingua que já estão lá como saber, vão bem além de tudo que o ser que fala é suscetível de enunciar. (p. 492)

Nesse processo em que o infans se encontra submerso na melodia de lalangue, a voz materna faz marcas nesse pequeno corpo que ainda não pertence a um sujeito, pois este ainda não pôde advir enquanto tal. As marcas de lalangue no corpo irão constituir a fantasia fundamental ou originária.

Quanto à melodia de alingua, faz-se necessário enfatizar que o campo de gozo ao qual o infans se encontra submetido quando está envolto nos embalos dessa sonoridade é um gozo Outro, e, portanto, completamente fora de sentido e fora da linguagem. Nesse tempo primordial, a palavra ainda não foi transmitida, mas já se verifica a transmissão de uma marca que diz respeito à origem e que se instalará como uma raiz sobre a qual a palavra virá a germinar em outro tempo. Essa raiz, que podemos considerar como sendo uma marca, não poderia ser o traço unário enquanto forma elementar do significante que dá conta dos primórdios da identificação simbólica ao Outro?

A partir dessa observação, poderíamos deduzir que, em lalangue, o infans encontra-se capturado por um gozo que é Outro e que isto ocorre pelo fato de estar completamente identificado ao Outro, de modo a juntos formarem Um. Essa "Unidade" proporcionaria certo enraizamento que deixaria traços, marcas primordiais que se marcariam como tatuagem, traço unário, matriz da identificação simbólica ao Outro.

Retomando: as marcas de lalangue no corpo irão constituir a fantasia fundamental ou originária, assim como também é importante retomar que lalangue diz respeito a um tempo mítico que corresponde a um gozo Outro e que possibilita o surgimento de uma identificação primordial a esse Outro e que terá por resultante um significante mestre $\left(\mathrm{S}_{1}\right)$ que possibilitará a entrada no campo simbólico e, portanto, campo da linguagem.

Aqui podemos notar um ponto de divisão no que diz respeito ao campo dos gozos: as marcas de lalangue no corpo estarão referenciadas a um tempo de identificação total ao Outro, o que se evidenciará no corpo gozante como sendo um gozo Outro, fora de toda e qualquer representação, ou seja, lugar de um real absoluto. A fantasia fundamental ou originária se edificará aqui com o intuito de tornar esse gozo ilimitado em um gozo limitado. O significante mestre $\left(\mathrm{S}_{1}\right)$, que irá também surgir dessa identificação total ao Outro, será o responsável por orientar a inserção no campo da linguagem, sendo, desta forma, um significante de comando e orientação, pois a partir dele o sujeito 
se fará representar para outros significantes, de modo que o gozo advindo da habitação desse lugar será fálico pelo fato de se referir à afirmação contínua de uma unidade.

A fantasia originária ou fundamental se diferencia das outras construções fantasísticas no sentido de que essa se funda em lalangue, quando a voz materna faz marcas no corpo da criança juntamente com o olhar. Nesse momento ainda não há sujeito, de modo que essas marcas irão se converter em signo, caso o infans não se aproprie delas, bem como irão se fundar enquanto significante, se houver uma apropriação por parte deste. Já a fantasia, que está na base do sintoma neurótico, será efeito do significante e irá se constituir a partir da instalação do significante mestre, que o sujeito, fundado a partir desse momento junto com esse significante $\left(\mathrm{S}_{1}\right)$ irá utilizar para se apresentar diante de outros significantes e, com isso, sair do gozo ilimitado no qual se encontrava absolutamente mergulhado no campo do Outro. A fantasia se constituirá aqui para limitar esse gozo e, com isto, instalar uma falta que possibilitará a esse sujeito se constituir como desejante.

Essa limitação de gozo se dá precisamente pela ação do Nome-do-Pai, que possibilitará o recalque originário e, consequentemente, a instauração da matriz psíquica denominada fantasia fundamental que consistirá numa forma fixa e repetitiva de o sujeito se relacionar com a causa do desejo. Para Lacan, a fantasia fundamental é concebida como "o que instaura o lugar onde o sujeito pode se fixar como desejo" (apud Jorge, 2010, p. 79). Assim, a fantasia fundamental seria o precipitado do desejo do Outro, que apontaria o lugar ao sujeito como seu objeto, de modo que, a partir dela, o "objeto causa de desejo" do sujeito se inscreveria ao mesmo tempo em que este mesmo sujeito também se inscreveria no lugar de objeto do Outro.

Lacan é bastante categórico ao dizer que o mais íntimo é êxtimo, pois, no que se refere à fantasia, não haveria interno e nem externo, e isso se verifica justamente pelo modo como a fantasia se constitui. Assim, em determinado momento de sua teorização, ele fará uso de um objeto topológico denominado banda de Moebius para apontar que o sujeito não seria nada mais que um corte que manifesta um dentro e fora.

É interessante notar o modo como o artista consegue "dar voz" ao inconsciente através de sua arte, como é o caso de Lygia Clark, artista mineira nascida em 1920. A partir de sua obra Caminhando, a artista nos remete à proposta da fita de Moebius de Lacan, apresentando um trabalho em que faz na fita unilateral, com uma tesoura, um corte transversal que não reencontra seu ponto de partida, mas prossegue sempre em uma nova volta, 
tornando sua largura cada vez mais fina e seu diâmetro cada vez maior, prolongando e expandindo a torção da banda em direção a uma ruptura final (Rivera, 2014).

Com Caminhando, Lygia Clark se propõe a ultrapassar a distinção entre dentro e fora, bem como entre sujeito e objeto, possibilitando uma reflexão artística acerca de tais instâncias, de modo que, se fôssemos fazer uma leitura de sua obra em termos psicanalíticos, a fantasia seria o centro de sua proposta (idem).

Como em Caminhando, a arte requer a participação do sujeito para se "dar a ver". Clark oferece uma proposta de dissolução do objeto em favor do ato, desmaterializando o eu e colocando-o em crise. A proposta se apresenta como uma subversão que propõe "um despertar do sujeito de sua alienação especular". Esse sujeito ao qual Caminhando convoca, "retoma em ato a fantasia e opera nela um reviramento: a fantasia deixa de ser a tela a encobrir o real, para se afirmar como corte que convoca sujeito e objeto a se (re)desprenderem, ambos subvertidos, descentrados, decaídos" (idem, p. 145). Nas palavras da própria artista encontramos o eco daquilo que sua arte personificava: "Quando me vi no espelho descobri maravilhada que minha 350 cara, que há muito havia perdido, estava lá, olhando para mim; foi como se me reencontrasse depois de viver 'o outro' tanto tempo" (Clark, 1970, apud Barbieri, 2008, p. 40).

Desse modo, o que podemos apreender a partir da proposição de Lygia Clark nos remete ao próprio ato de fundação do sujeito, no sentido em que recobra o momento de unificação subjetiva em que o infans é Um com o Outro, e, a partir de um corte, que é sempre da ordem de um ato, esse processo de separação, sempre contínuo, começa a se dar... Caminhando... Sempre caminhando... A separação é contínua... Caminhando... Porém o Outro permanece... A fantasia nos mostra que o Outro permanece... Dentro e fora... Sujeito e objeto.

\section{Considerações finais}

O corpo seria efeito da escrita da fantasia ou efeito daquilo que da fantasia não se escreve?

Compreendemos até aqui que o sujeito se constitui em uma relação contínua de alienação e separação ao Outro da linguagem e que a pulsão justamente seria efeito desse processo. Para Lacan (1962-63/2005), a pulsão 
seria o efeito da demanda do Outro da linguagem, em uma incidência ainda muito precoce sobre o sujeito em constituição.

Como vimos, o sujeito depende do significante e o significante está primeiro no campo do Outro, fazendo parte do processo da constituição da fantasia, pois nesse campo do Outro, que é o campo do vivo, encontramos a libido, que tem como representante todas as formas possíveis de objeto $a$, objeto da fantasia. Desdobrando a fórmula da fantasia $\$ \diamond a$, ficou evidenciado que o sujeito barrado tem em suas bordas o objeto $a$, ou seja, o sujeito que é barrado pela ação do significante Nome-do-Pai passa a fazer bordas com $a$, o objeto faltoso, o qual lhe aponta que, a partir desse momento, há uma falta. Essa falta passará, a partir daí, a estar localizada no corpo desse sujeito, de modo que a fantasia também passará a se presentificar nesse corpo.

Segundo Lacan (1962-63/2005), aquilo que não puder ser projetado e nem investido na imagem especular será irredutível a ela, pois permanecerá profundamente investido no próprio corpo, no campo do gozo concernente ao narcisismo primário, o que significa precisamente que a falta restará localizada no corpo. Assim, o corpo seria uma forma de escrita que teria como proposta inscrever o traço unário, isto é, o signo do Outro que esse traço inaugura.

A inscrição do traço unário enquanto signo do Outro se dá em lalangue, momento em que o infans encontra-se submerso nessa melodia, nos embalos dessa sonoridade e, portanto, submetido a um gozo Outro, completamente fora do sentido e fora da linguagem. As marcações que ocorrem no pequeno corpo desse "protosujeito" nesse momento, por serem da ordem de lalangue, apontam para um gozo Outro, sendo que as marcas de lalangue no corpo irão constituir a fantasia fundamental ou originária.

Ocorre que essa fantasia fundamental ou originária justamente se edificará aqui, nas bases de lalangue, para tornar esse gozo ilimitado em gozo limitado. A partir disso, o sujeito se situará no campo da linguagem, de modo que o gozo advindo desse lugar será fálico, por se referir à afirmação contínua de uma unidade; a partir desse ponto, se instalará a fantasia propriamente dita, base do sintoma, que inaugurará uma falta possibilitando ao sujeito se constituir como desejante.

Aqui cabe a questão se o corpo seria efeito de uma escrita da fantasia ou daquilo que da fantasia não se escreve. A partir dos desdobramentos efetuados ao longo da pesquisa, chegamos às seguintes deduções: o corpo seria efeito de ambas as possibilidades, ou seja, seria construído tanto a partir do que é da 
ordem de uma escrita, ou seja, de uma tentativa de inscrição daquilo que não se escreve, como também seria efeito daquilo que não se escreve e, portanto, resta irredutível no próprio corpo.

O corpo é produto da linguagem, mas também diz respeito a um mais além da linguagem, de modo que pode ser entendido como um corpo erógeno que a fantasia circunscreve e também como um corpo que escapa a isso. Assim, é possível verificar a emergência de um corpo que tenta, a partir da fantasia, responder ao "Que queres?" (pergunta que o sujeito endereça ao Outro da linguagem), e um corpo que inelutavelmente não consegue responder a nada nem a ninguém e nem se dispõe a isso, pois não habita o campo da linguagem e, portanto, nele não cabem tentativas de perguntas e respostas.

Portanto, estamos falando de um corpo que foi constituído em lalangue, tendo por base a sonoridade e referindo-se a um gozo Outro que escapa ao campo da linguagem. Esse corpo diz respeito à constituição da fantasia fundamental ou originária e, portanto, fala daquilo que da fantasia não se escreve. Mas também estamos nos referindo a um corpo que está inscrito na linguagem e tem sua constituição relacionada com o gozo 352 fálico, que se estabeleceu com o intuito de limitar um gozo que até então era ilimitado. Aqui se trata de um corpo que corresponde a uma escrita da fantasia, pois esse corpo estabelece suas bordas a partir da constituição fantasística que se fundamenta em seu "diálogo" com o Outro, na tentativa de responder ao desejo do Outro e numa busca contínua pelo objeto perdido, causa de desejo.

Desse modo, o corpo é efeito da escrita da fantasia e também daquilo que da fantasia não se escreve. A fantasia originária seria marca, traço fixado no corpo; e a fantasia secundária estaria no corpo enquanto escrita.

Agradecimentos: Agradeço primeiramente minha orientadora Ana Maria Medeiros da Costa que, indubitavelmente, foi aquela que possibilitou que esta pesquisa viesse a ser uma escrita.

Agradeço igualmente ao programa de pós-graduação em psicanálise da UERJ e todo seu corpo docente e discente, que me ofereceram um espaço onde pude encontrar rigor teórico e confiança para levar adiante o avanço deste projeto.

Por fim, agradeço a CAPES que me concedeu o auxilio financeiro necessário para efetivar esta pesquisa. 


\section{ARTIGOS}

\section{Referências}

Barbieri, C. P. (2008). Lygia Clark, da vida à arte e de volta à vida. Estudos de Psicanálise, (31), 36-42. Recuperado de: <https://pepsic.bvsalud.org/scielo. php?script=sci_arttext\&pid=S0100-34372008000100005\&lng=pt\&tlng=pt $>$.

Freud, S. (2007a). La represión. In Obras completas (vol. XIV). Buenos Aires, AR: Amorrortu. (Trabalho original publicado em 1915).

Freud, S. (2007b). Pulsiones y destinos de pulsión. In Obras completas (vol. XIV). Buenos Aires, AR: Amorrortu. (Trabalho original publicado em 1915).

Jorge, M. A. C. (2000). Fundamentos da psicanálise de Freud a Lacan: as bases conceituais. Rio de Janeiro, RJ: Zahar.

Jorge, M. A. C. (2010). Fundamentos da psicanálise de Freud a Lacan: a clínica da fantasia. Rio de Janeiro, RJ: Zahar.

Lacan, J. (2003). O aturdito. In Outros escritos. (Vera Ribeiro, trad.; pp. 448-497). Rio de Janeiro, RJ: Zahar. (Trabalho original publicado em 1973).

Lacan, J.(2005). O seminário. Livro 10. A angústia.Rio de Janeiro, RJ: Zahar. (Trabalho original publicado em 1962-63).

Lacan, J. (2007). O seminário. Livro 23. O sinthoma. Rio de Janeiro, RJ: Zahar. (Trabalho original publicado em 1975-76).

Lacan, J. (2008a). O seminário. Livro 11. Os quatro conceitos fundamentais da psicanálise. Rio de Janeiro, RJ: Zahar. (Trabalho original publicado em 1973).

Lacan, J. (2008b). O seminário. Livro 20. Mais, ainda. Rio de Janeiro, RJ: Zahar. (Trabalho original publicado em 1975).

Mieli, P. (2002). Sobre as manifestações irreversiveis do corpo e outros textos psicanalíticos. Rio de Janeiro, RJ: Contra Capa.

Rivera, T. (2014). O avesso do imaginário: arte contemporânea e psicanálise. São Paulo, SP: SESI-SP.

\section{Resumos}

(The body as a product of writing in fantasy)

This research examines the relationship of the body to writing and to fantasy to find out to what extent the body may be either the effect of fantasy writing or a product of what is not written from fantasy. Writing leaves traces that guide to the path of the drive and may reveal signs of supports and body constructions, highlighting the fantasy that is at its foundation.

Key words: Body, writing, fantasy, lalangue 
(Le corps comme produit de l'écriture dans le fantasme)

Cette recherche vise à articuler la relation entre corps, écriture et fantasme, cherchant à vérifier dans quelle mesure le corps peut être effet d'une écriture du fantasme ou produit de ce que du fantasme ne s'écrit pas. L'écriture laisse des traces qui indiquent le chemin de la pulsion et peuvent révéler des indices de supports et de constructions corporelles, révélant ainsi le fantasme qui se trouve à son origine.

Mots clés: Corps, écriture, fantasme, lalangue

(El cuerpo como producto de la escritura de la fantasía)

Esta investigación propone articular la relación entre el cuerpo, la escritura y la fantasía, buscando verificar hasta qué punto el cuerpo puede ser el efecto de una escritura de la fantasía o el producto de lo que no se escribe de la fantasía. La escritura deja huellas que señalan el rumbo de la pulsión y pueden revelar indicios de los soportes y de las construcciones corporales, revelando la fantasía que se encuentra en su base.

Palabras clave: Cuerpo, escritura, fantasía, lalangue

Citação/Citation: Mattos, J. B. de, \& Costa, A. M. M. da (2021, junho). O corpo enquanto produto da escrita na fantasia. Revista Latinoamericana de Psicopatologia Fundamental, 24(2), 333-355. http://dx.doi.org/10.1590/1415-4714.2021v24n2p333.6.

Editora/Editor: Profa. Dra. Sonia Leite

Submetido/Submitted: 2.6.2020 / 6.2.2020 Revisado/Revised: 25.8.2020 / 8.25.2020

Aceito/Acepted: $15.11 .2020 / 11.15 .2020$

Copyright: (C) 2009 Associação Universitária de Pesquisa em Psicopatologia Fundamental/ University Association for Research in Fundamental Psychopathology. Este é um artigo de livre acesso, que permite uso irrestrito, distribuição e reprodução em qualquer meio, desde que o autor e a fonte sejam citados / This is an open-access article, which permits unrestricted use, distribution, and reproduction in any medium, provided the original authors and sources are credited.

Financiamento/Funding: Este trabalho recebeu apoio da Coordenação de Aperfeiçoamento de Pessoal de Nivel Superior - Capes (Brasília, DF, Br) / This work is supported by Coordenação de Aperfeiçoamento de Pessoal de Nivel Superior - Capes (Brasília, DF, Br). 


\section{ARTIGOS}

Conflito de interesses/Conflict of interest: As autoras declaram que não há conflito de interesses. / The authors declare that there is no conflict of interest.

Janaina Bianchi de Mattos

Mestra e Doutoranda em Psicanálise pelo Programa de Pós-Graduação em Psicanálise (PPGP) da Universidade do Estado do Rio de Janeiro - UERJ (Rio de Janeiro, RJ, Br).

Rua Doutor Paulo Cesar, 87 - Bloco 2 - apto. 903 - Icaraí

24220-401 Niterói, RJ, Br

janainabianchi@yahoo.com.br

https://orcid.org/0000-0002-5227-5415

Ana Maria Medeiros da Costa

Doutora em Psicologia Clínica pela Pontifícia Universidade Católica de São Paulo PUC-SP (São Paulo, SP, Br); Professora do Programa de Pós-Graduação em Psicanálise (PPGP) da Universidade do Estado do Rio de Janeiro - UERJ (Rio de Janeiro, RJ, Br). Concluiu o Pós-doutorado na Université Paris 13. Coordenadora da Rede de Pesquisa Interuniversitária Escritas da Experiência (CNPq).

Rua Doutor Paulo Cesar, 87 - Bloco 2 - apto. 903 - Icaraí

24220-401 Niterói, RJ, Br

medeirosdacostaanamaria@gmail.com

https://orcid.org/0000-0002-9518-0424

This is an open-access article, which permits unrestricted use, distribution,

\section{(cc) BY-NC} and reproduction in any medium for non-commercial purposes provided the original authors and sources are credited. 